\title{
PERAN GURU DALAM MENGEMBANGKAN KECERDASAN MUSIKAL ANAK USIA DINI MELALUI KEGIATAN EKSTRAKURIKULER DRUMBAND DI TK MUSLIMAT NU 001 PONOROGO
}

\author{
Amin Mahmudah \\ Institut Agama Islam Negeri Ponorogo \\ Email:aminmahmudah41@gmail.com \\ Umi Rohmah \\ Institut Agama Islam Negeri Ponorogo \\ Email: umi_rohmah@iainponorogo.ac.id
}

\begin{abstract}
Musical intelligence of a child's ability to store notes, remember rhythm and be emotionally affected by music. The development of musical intelligence is one of them by the drumband extracurricular activities. This study aims to: (1). know the role of the teacher as a facilitator in developing early childhood musical intelligence through Drumband Extracurricular activities at Muslimat Nu 001 Ponorogo Kindergarten. (2). know the role of the teacher as a guide in developing musical intelligence of Early Childhood through Drumband Extracurricular activities at Muslimat Nu 001 Ponorogo Kindergarten. This research uses a qualitative approach with case study research. The technique used in collecting data is to use observation, interview, and documentation techniques. While the data analysis technique used is to use the Milles Hiberman technique. The results of this study are (1) the teacher's role as a facilitator is as a provider of the tools needed during the exercise and checking the condition of the tools. (2) the teacher's role as a guide in is to provide guidance and train children in the technique of punching in accordance with the tempo, training and accustoming children to discipline in drum exercises.
\end{abstract}

Keywords: Teacher Role, Musical Intelligence, Extracurricular Activities

\begin{abstract}
Abstrak: Kecerdasan musikal kemampuan anak untuk menyimpan nada, mengingat irama dan secara emosional terpengaruh oleh musik. Pengembangan kecerdasan musikal salah satunya adalah dengan kegiatan ekstrakurikuler drumband. Penelitian ini bertujuan untuk: (1). mengetahui peran guru sebagai fasilitator dalam mengembangkan kecerdasan musikal Anak Usia Dini melalui kegiatan Ekstrakurikuler Drumband di TK Muslimat Nu 001 Ponorogo. (2). mengetahui peran guru sebagai pembimbing dalam mengembangkan kecerdasan musikal Anak Usia Dini melalui kegiatan Ekstrakurikuler Drumband di TK Muslimat Nu 001 Ponorogo. Penelitian ini menggunakan pendekatan kualitatif dengan penelitian studi kasus. Adapun teknik yang digunakan dalam mengumpulkan data adalah menggunakan teknik observasi, wawancara, dan dokumentasi. Sedangkan teknik analisis data yang digunakan adalah dengan menggunakan teknik Milles Hiberman. Adapun hasil penelitian ini adalah (1) peran guru sebagai fasilitator adalah sebagai penyedia alat yang dibutuhkan selama latihan berlangsung dan mengecek kondisi alat. (2) peran guru sebagai pembimbing dalam adalah memberikan bimbingan dan melatih anak dalam teknik pukulan sesuai tempo, melatih dan membiasakan anak untuk disiplin dalam latihan drumband.
\end{abstract}

Kata kunci: Peran Guru, Kecerdasan Musikal, Kegiatan Ekstrakurikuler. 


\section{PENDAHULUAN}

Pendidik adalah orang yang mempunyai peranan penting dalam pendidikan. Agar proses pendidikan dapat berjalan dengan efektif dan efisien, pendidik dituntut untuk memiliki kompetensi. Kompetensi tersebut meliputi kompetensi pedagogik, kompetensi sosial, kompetensi profesional dan kompetensi kepribadian. Kompetensi itulah yang akan digunakan untuk menilai apakah seorang pendidik itu berkualitas atau tidak dan menjadi gambaran tentang apa saja yang sekiranya dapat dilakukan pendidik dalam melaksanakan pekerjaannya. Sertifikasia dalah suatu proses pemberian sertifikat atau penghargaan pendidik untuk guru dan dosen. Sedangkan sertifikasi pendidik adalah bukti formal sebaga ipengakuan yang diberikan kepada guru dan dosen sebagai tanda profesional. $^{1}$

Dalam PP No. 74 Tahun 2008 disebutkan, guru wajib memiliki kualifikasi akademik, kompetensi, sertifikat pendidik, sehat jasmani dan rohani, serta kemampuan untuk mewujudkan tujuan pendidikan nasional. Kompetensi profesional yang dimaksudkan adalah kemampuan guru dalam menguasai pengetahuan atau bidang ilmu pengetahuan, teknologi, seni budaya yang diampunya dan sekurang-kurangnya meliputi penguasaan materi pelajaran serta konsep metode disiplin keilmuan. Hal ini sesuai dengan Undang-undang RI Nomor 14 Tahun 2005 tentang Guru dan Dosen Pasal 8 bahwa Guru wajib memiliki kualifikasi akademik, kompetensi, sertifikasi pendidik, sehat jasmani dan rohani serta memiliki kemampuan untuk mewujudkan tujuan pendidikan nasional. ${ }^{2}$

Teori Multiple Intellegencies (kecerdasan ganda) dari Gardner menyatakan ada delapan tipe kecerdasan yang meliputi kecerdasan matematika logika, kecerdasan bahasa, kecerdasan musikal, kecerdasan visual spasial, kecerdasan kinestetik, kecerdasan interpersonal, 
kecerdasan intrapersonal dan kecerdasan naturalis. Biasanya seorang anak memiliki beberapa kecerdasan, tetapi sangat jarang yang memiliki secara sempurna delapan kecerdasan tersebut. Oleh karena itu, PAUD diarahkan untuk memfasilitasi setiap anak dengan lingkungan dan bimbingan belajar yang tepat agar anak dapat berkembang sesuai kapasitas genetisnya. ${ }^{3}$

Kecerdasan musikal adalah kemampuan untuk menyimpan nada, mengingat irama, dan secara emosional terpengaruh oleh musik. Kecerdasan musikal berkaitan dengan merasakan, mengubah, dan membeda-bedakan berbagai format musik/ nada, termasuk sensitivitas dalam merasakan ritme, tinggi rendah dan warna nada. ${ }^{4}$ Sayangnya, sekolah-sekolah atau pendidikan di negeri ini tidak memasukkan pelajaran musik sebagai mata pelajaran yang serius. Bernyanyi pun hanya sebatas pada lagu-lagu nasional yang sering kali kurang menarik. Akhirnya pelajaran musik semakin dikesampingkan dan dianggap tidak begitu penting. ${ }^{5}$

Kecerdasan musikal pada anak dapat dikembangkan dalam kegiatan ekstrakurikuler di sekolah. Ekstrakurikuler merupakan kegiatan di luar jam pelajaran yang bertujuan membantu perkembangan peserta didik sesuai dengan potensi, bakat dan minat anak. ${ }^{6}$ Salah satu kegiatan ekstrakurikuler yang dapat mengembangkan kecerdasan musikal anak adalah drumband. Drumband merupakan sekelompok barisan orang yang memainkan satu atau beberapa lagu dengan menggunakan sejumlah kombinasi alat musik, seperti tiupan, perkusi, dan sejumlah instrumen pit

${ }^{3}$ SlametSuyanto, Dasar-DasarPendidikanAnakUsiaDini (Yogyakarta: Hikayat Publishing, 2005), $1-5$.

4 Aziz Safa, 144 Strategi Pembelajaran Anak Usia Dini Berbasis Multiple Intelligences, (Yogyakarta: Ar-ruzz Media), 355.

${ }^{5}$ Suyadi, Teori Pembelajaran Anak Usia Dini, (Bandung: PT Remaja Rosdakarya, 2014), 130-131.

${ }^{6}$ Jamal Ma'mur Asmani, Kiat mengembangkan Bakat Anak di Sekolah, (Yogyakarta: Diva Press, 2012), 152. 
secara bersamaan dan diiringi oleh mayoret sebagai pemimpin. ${ }^{7}$ Jadi kegiatan ekstrakurikuler drumband adalah kegiatan yang dilakukan diluar jam mata pelajaran yang memainkan beberapa lagu dengan menggunakan kombinasi alat musik seperti tiupan, alat perkusi dan instrument alat pit secara bersamaan, dengan dipimpin oleh satu atau dua mayoret yang bertugas sebagai komandan lapangan dan sejumlah pemain yang membawa bendera yang membentuk formasi. Kegiatan ekstrakulikuler drumband menjadi wadah terbaik dalam mengembangkan potensi dan bakat siswa dalam bermusik. ${ }^{8}$

Berdasarkan observasi pendahuluan dan wawancara langsung dengan Ibu Hanik Masadah, S.Pd selaku kepala sekolah pada hari Senin tanggal 5 November 2018 diperoleh informasi bahwaTK Muslimat NU Ponorogo memiliki beberapa kegiatan ekstrakurikuler, seperti drumband, baca tulis dan sempoa. Berbagai kegiatan ekstrakurikuler tersebut dilaksanakan agar potensi kecerdasan yang dimiliki anak dapat tersalurkan dengan tepat dan berkembang dengan baik. Wawancara selanjutnya dengan Bapak Agus Efendi selaku pembina kegiatan ekstrakurikuler drumband pada pada hari Senin tanggal 5 November 2018 diperoleh informasi bahwa TK Muslimat NU Ponorogo memberikan perhatian terhadap kecerdasan musikal anak yang dikembangkan melalui kegiatan ekstrakurikuler drumband. Tujuan ekstrakurikuler drumband ini adalah memberikan wadah kepada anak untuk mengembangkan minat dan bakat dalam bermusik, dan menjadi kegiatan ekstrakurikuler tervavorit dari kegiatan ekstrakurikuler yang lainnya dan mendapat perhatian yang baik dari kepala sekolah.

\footnotetext{
${ }^{77}$ AndroMediawan, dkk, Ragam Ekskul Bikin Kamu Jadi Bintang, (Yogyakarta: BukuBiru, 2012), 40.

${ }^{8}$ ZulfatulRifqoh, "Pengembangan kecerdasan musical pada siswa melalui kegiatan ekstrakurikuler marching band di Mi Negeri Model Slarang Kidul Kecamatan Lebaksiu Kabupaten Tegal",

(Skripsi: IAIN Purwokwerto, 2016), 4-5.
} 
Kecerdasan musical anak di TK Muslimat NU 001 Ponorogo telah berkembang dengan baik. Anak sudah mampu mengembangkan kecerdasan musical dengan bimbingan guru yang setiap minggu mengadakan latihan kegiatan ekstrakurikuler drumband. Kemampuan anak dalam menangkap not ataupun nada yang dimainkan berbeda-beda. Ada yang kecerdasan musicalnya rendah sehingga terlihat lambat dalam menghafal not lagu dan memainkan alat drumband. Pada kategori sedang anak dapat dengan mudah menghafal not dan memainkan alat yang diajarkan pembimbing drumband. Pada kategori tinggi anak dapat langsung dengan mudahnya menghafal not dan bisa langsung mempraktikannya dalam permainan alat music drumband sehingga pembimbing tidak membutuhkan waktu yang lama dalam melatih drumband.

\section{METODE PENELITIAN}

Dalam penelitian ini digunakan metode dengan pendekatan kualitatif, yang memiliki karakteristik alami (natural setting) sebagai sumber data langsung, manusia sebagai intrumen, deskriptif, proses lebih dipentingkan dari pada hasil, analisis dalam penelitian kualitatif cenderung dilakukan secara induktif dan lebih mementingkan proses daripada hasil. 'Jenis penelitian yang digunakan ialah penelitian studi kasus, yakni suatu penelitian yang berusaha menemukan makna, menyelidiki proses, dan memperoleh pengertian dan pemahaman yang mendalam dari individu, kelompok, atau situasi. ${ }^{10}$ Tenik pengumpulan data merupakan cara yang digunakan peneliti dalam mengumpulkan fakta dan informasi yang ada di lapangan yang dapat digunakan sebagai penunjang dalam penelitian. Dalam penelitian kualitatif peneliti harus terjun sendiri ke lapangan untuk memperoleh data. ${ }^{11}$ Dalam penelitian ini teknik pengumpulan data penelitian sebagai berikut : Wawancara, Observasi,

\footnotetext{
${ }^{9}$ Lexy J. Moleong, MetodePenelitianKualitatif (Bandung: PT RemajaRosdakarya, 2008), 8

${ }^{10}$ Emzir, MetodologiPenelitianKalitatifAnalisisData (Jakarta: PTGrafindoPersada, 2010), 20.

${ }^{11}$ Ibid.,167
} 
Dokumentasi. Analisis data diartikan sebagai upaya mengolah data menjadi informasi, sehingga karakteristik atau sifat-sifat data tersebut dapat dengan mudah dipahami dan bermanfaat untuk menjawab masalahmasalah yang berkaitan dengan kegiatan penelitian. ${ }^{12}$ Teknik analisis data yang digunakan dalam penelitian ini adalah menggunakan konsep Milles dan Huberman yang mengemukakan tiga tahapan yaitu reduksi data, penyajian data, dan penarikan kesimpulan.

\section{TEMUAN DAN PEMBAHASAN}

Pembahasan tentang peran guru sebagai fasilitator dalam mengembangkan kecerdasan musikal Anak Usia Dini melalui Kegiatan Ekstrakurikuler Drumband di TK Muslimat NU 001 Ponorogo.

Guru merupakan tokoh sentral bagi kepribadian peserta didik. Anak akan meneladani dan menerima ucapan guru dalam pembelajaran. Dalam konteks penggalian dan pengembangan bakat anak didik, peran guru sangat penting. Tentu, kita menginginkan seorang guru mampu mengenal bakat anak didik dan mengarahkan bakat tersebut ke tempat yang benar. Memang, pada zaman dahulu guru mampu membuka tirai hati anak didiknya, sehingga mereka terbuka mata hatinya menuju tangga kesuksesan dunia akhirat. Dengan demikian, guru harus mengetahui bagaimana perkembangan anak didik agar mampu menaiki level tersebut di masa Taman Kanak-Kanak. ${ }^{13}$

Kegiatan ekstrakurikuler drumband membantu siswa dalam mengembangkan ketrampilan dan bakat yang dimiliki oleh siswa. Dalam kegiatan ekstrakurikuler drumband terdapat aktifitas TK Muslimat NU 001 Ponorogo merupakan salah satu sekolah yang mengembangkan kecerdasan musikal anak melalui kegiatan ekstrakurikuler drumband.

\footnotetext{
${ }^{12}$ Wulansari, PenelitianPendidikan: SuatuPendekatanPraktikdenganMenggunakan SPSS, 97

${ }^{13}$ Asmani, Kiat Mengembangkan Bakat Anak di Sekolah, 111
} 
Kegiatan ekstrakurikuler drumband terdapat aktivitas bernyanyi, bermain notasi musik, bermain alat musik, berlatih menari mengikuti irama musik yang dimainkan yang merupakan cara untuk mengembangkan kecerdasan musikal pada anak.

Peran guru sebagai fasilitator adalah mempersiapkan semua alat yang menunjang kegiatan ektrakurikuler drumband. Di TK Muslimat NU 001 Ponorogo dalam kegiatan latihan drumband di setiap alat musik yang dimainkan terdapat pembimbing yang bertugas mengarahkan dan membantu anak ketika mengalami kesulitan. Di bagian penari guru sebagai fasilitator berperan sebagai penyedia kostum sesuai dengan ukuran badan anak, mengganti kostum yang sudah tidak layak dan membantu anak dalam mengolah tubuh dalam menari. Pada bagian gita pati guru sebagai fasilitator berperan penyedia alat berupa stik mayoret.

Guru sebagai fasilitator dalam alat musik perkusi menyiapkan alat berupa stik, tenor, snardrum, dan mengecek kondisi alat hingga siap digunakan. Pada bagian bass guru berperan sebagai penyedia alat dan megecek apakah alat yang digunakan layak atau tidak. Peran guru sebagai fasilitator pada alat musik bellyra adalah mencatatkan notasi lagu yang dimainkan. Pada bagian bendera guru menyiapkan bendera yang akan digunakan hingga semua persiapan lengkap.

\section{Peran guru sebagai pembimbing dalam mengembangkan kecerdasan musikal Anak Usia Dini melalui Kegiatan Ekstrakurikuler Drumband di TK Muslimat NU 001 Ponorogo.}

Berkenaan dengan peran guru drumband sebagai pembimbing dalam mengembangkan kecerdasan musikal anak usia dini melalui kegiatan ekstrakurikuler drumband guru diminta untuk mengarahkan siswa untuk dapat memainkan alat dengan baik dan benar, membimbing anak dalam menyelaraskan gerakan pada penari dan mayoret sehingga dapat dihasilkan tarian yang indah. 
Guru sebagai pembimbing haruslah bisa menunjukkan pada anak bagaimana agar anak dapat belajar dengan baik, dengan benar sesuai dengan prosedur yang ada. Tanpa bimbingan dari seorang guru anak akan mengalami banyak kesulitan dan biasanya anak yang kurang dalam bimbingan anak akan lebih bergantung pada teman karena anak tersebut merasa bingung dan masih belum menguasai apa yang dipelajari. Pembimbingan yang dilakukan oleh guru harus menyatu dengan proses pembelajaran agar mencapai tujuan yang diinginkan dan menjadi faktor penentu keberhasilan anak dalam belajar.

\section{KESIMPULAN}

Dari hasil penelitian terkait peran guru drumband dalam mengembangkan kecerdasan musikal anak melalui kegiatan ekstrakurikuler drumband di TK Muslimat NU 001 Ponorogo, dapat diambil kesimpulan bahwa:

1. Peran guru sebagai fasilitator dalam mengembangkan kecerdasan musikal anak usia dini di TK Muslimat NU 001 Ponorogo adalah sebagai penyedia alat yang dibutuhkan selama latihan berlangsung, mengecek kondisi dan kelayakan alat hingga siap untuk digunakan, dan menyediakan kepada anak notasi lagu yang ditulis dipapan tulis maupun dicetak dalam bentuk print di kertas agar anak lebih mudah dalam mengingat dan mempelajari notasi lagu yang dimainkan.

2. Peran guru sebagai pembimbing dalam mengembangkan kecerdasan musikal anak usia dini di TK Muslimat NU 001 Ponorogo adalah memberikan bimbingan dan melatih anak dalam teknik pukulan sesuai tempo, melatih dan membiasakan anak untuk disiplin dalam latihan, memberikan arahan anak agar mengembangkan kemampuan dalam olah tubuh dengan menyelaraskan dengan lagu yang dimainkan terutama yang 
menjadi petugas gita pati dan mayoret, memberikan bimbingan kepada anak disaat anak mengalami kesulitan dalam latihan drumband.

\section{DAFTAR PUSTAKA}

Asmani, Jamal Ma'mur. 2012. Kiat mengembangkan Bakat Anak di Sekolah, Yogyakarta : Diva Press.

Emzir. 2010. Metodologi Penelitian Kalitatif Anaisis Data. Jakarta: PT Grafindo Persada.

Moleong, Lexy J. 2008. Metode Penelitian Kualitatif. Bandung: PT RemajaRosdakarya.

Riyadi Santoso. 2017. Metode Penelitian Kualitatif Kebahasaan. Surakarta: UNS Press.

Safa, Aziz. 2017. Strategi Pembelajaran Anak Usia Dini Berbasis Multiple Intelligences. Yogyakarta : Ar-ruzzmedia

Sugiyono. 2012. MetodologiPenelitianKualitatif, Dan R\&D. Bandung :Alfabeta.

Sugiyono. 2012. Metodologi Penelitian Kualitatif, Dan R\&D. Bandung : Alfabeta,.

Sugiyono. 2017. Metode Penelitian Pendidikan Kuantitatif, Kualitatif dan $R \& B$. Bandung : Alfabeta.

Suyanto, Slamet. 2005. Dasar-Dasar Pendidikan Anak Usia Dini. Yogyakarta : Hikayat Publishing.

Rifqoh, Zulfatul. 2016. "Pengembangan kecerdasan musikal pada siswa melalui kegiatan ekstrakurikuler marching band di Mi Negeri Model Slarang Kidul Kecamatan Lebaksiu Kabupaten Tegal". Skripsi: IAIN Purwokwerto. 